\title{
Some Developments of the Method to Apply Band Models
}

\section{to an Inhomogeneous Atmosphere}

\author{
By Tadao Aoki and Kiyotaka Shibata \\ Meteorological Research Institute, Tsukuba, Ibaraki 305, Japan \\ (Manuscript received 20 February 1990, in revised form 17 April 1990)
}

\begin{abstract}
An exact solution of the infrared radiative transfer through multi-homogeneous layers has been developed in the framework of a random band model for the Lorentz lines. Comparing with this solution the accuracy of the Curtis-Godson and Godson methods, which are currently used in calculating the radiative transfer through the inhomogeneous atmosphere, has been investigated. It has been shown that the error of the sequential procedure of Godson is variable depending on whether the transmittance is calculated upward or downward direction of the atmosphere.

A new sequential procedure has been proposed using the analytical exact solution for two layers. It is shown that this new sequential procedure is of better accuracy than the methods of Curtis-Godson and Godson for the radiative transfer calculation of water vapor, carbon dioxide and ozone.
\end{abstract}

\section{Introduction}

An absorption band of the atmospheric gases contains thousands of lines. To calculate the radiative transfer or heating rate efficiently the mean band transmittance is represented by band models. The band models idealize the line structure in the band and represent the mean transmittance by a simple analytical function. Since these models have originally been developed for a homogeneous path, some methods have to be developed further to apply them to the inhomogeneous atmosphere, where the temperature and pressure change with height.

The scaling method or the so-called CurtisGodson method (C-G method) (see Goody, 1964 or Goody and Yung, 1989) has currently been used for incorporating band models into the transmittance calculation of the inhomogeneous atmosphere. It is well known the accuracy of the C-G method is poor for the ozone band (Walshaw and Rodgers, 1963; Clark and Hitschfeld, 1964). Some investigations have been conducted to improve the transmission calculation of the inhomogeneous atmosphere (Goody, 1964; Goody and Yung, 1989; Yamamoto and Aida, 1970; Yamamoto et al., 1972; Kuriyan et $a l ., 1977)$. In the methods proposed in these papers an inhomogeneous path between two pressure levels is approximated by an equivalent homogeneous path with a constant pressure and temperature. Intuitively, in such approximations the error might be expected to become large when the pressure and

(C)1990, Meteorological Society of Japan temperature change greatly along the path.

On the other hand, a sequential procedure has been developed by Godson (1953), which calculates the transmittance through multi-homogeneous layers sequentially. Although this method is not supported on a rigorous mathematical basis, it has successfully been applied to the inhomogeneous atmosphere (Weinreb and Neuendorffer, 1973; Aoki, 1979; Shibata and Aoki, 1989). A theoretical discussion for multi-homogeneous layers has been developed by Plass (1965), where a formulation of the transmission function through two homogeneous layers has been developed based on the random band model with an exponential intensity distribution. However, as will be shown later, this formula cannot be reduced to a one-layer formula when the temperature and pressure of two layers become equal. Rodgers (1968) showed that, for two homogeneous layers, the transmission function of the random model with the Malkmus intensity distribution (Malkmus, 1967) results in an elegant formula.

In the present paper we will develop an exact solution of the transmission function for multihomogeneous layers in the framework of a random band model for two intensity distribution models; the exponential intensity distribution and the $S^{-1}$ tailed exponential intensity distribution (Malkmus model). For two layers the exact solution is reduced to fairly simple analytical functions so that we propose a practical method of sequential procedure using two-layer solutions. Finally the accuracies of this new sequential procedure, the Godson method and 


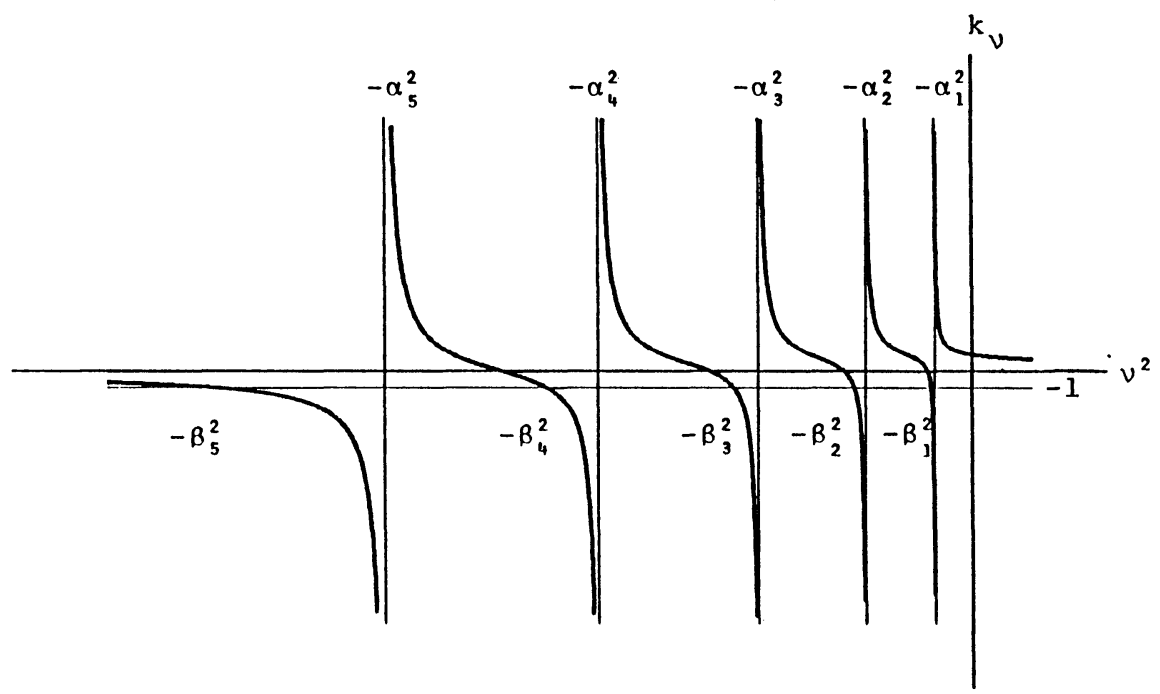

Fig. 1. The optical ihickness $k_{\nu}$ (thick lines) as a function of the negative value of $\nu^{2}$. The cross points with the horizontal line of -1 are $\beta_{i}^{2}$, appearing in Eq. (11) of the text.

the C-G method are compared for $\mathrm{H}_{2} \mathrm{O}, \mathrm{CO}_{2}$ and $\mathrm{O}_{3}$ absorption bands.

\section{Exact solution for multi-homogeneous lay- ers}

2.1 Formulation for the Malkmus random model

According to the random model (Goody, 1964; Goody and Yung, 1989) the mean transmittance of a band is given by

$$
\begin{aligned}
& \tilde{\mathcal{T}}=\exp (-A) \\
& A=\frac{1}{\delta} \int_{-\infty}^{\infty} d \nu \int_{0}^{\infty} d S\left[1-\exp \left(-\tau_{\nu}\right)\right] P(S),
\end{aligned}
$$

where $\delta$ is the band interval, $\nu$ the wavenumber, $S$ the line intensity and $\tau_{\nu}$ the optical depth. $P(S)$ is the probability function of the intensity, and in Malkmus model (Malkmus, 1967) it is given by

$$
P(S)=\frac{1}{S \ln R}\left[\exp \left(-\frac{S}{S_{M}}\right)-\exp \left(-\frac{R S}{S_{M}}\right)\right],
$$

where $R$ and $S_{M}$ are the constants. For $N$ homogeneous layers $\tau_{\nu}$ is given by

$$
\tau_{\nu}=\sum_{i=1}^{N} S_{i} a_{i} f_{i}(\nu)
$$

where $a_{i}$ and $f_{i}$ are the absorber amount and shape factor of the $i$-th layer, respectively. Here we assume that the intensity distribution function $P(S)$ is the same for each layer or, at most, the relative distribution is unchanged. That is, we assume that $S_{i}$ is given by

$$
S_{i}=S \gamma\left(T_{i}\right),
$$

where $\gamma$ is a function of the temperature of the $i$-th layer, $T_{i}$, and irrelevant to the values of $S$. By this assumption (4) reduces to

$$
\begin{aligned}
\tau_{\nu} & =S \sum_{i} a_{i}^{\prime} f_{i}(\nu), \\
a_{i}^{\prime} & =a_{i} \gamma\left(T_{i}\right) .
\end{aligned}
$$

When $P(S)$ is given by

$$
P(S)=\frac{1}{S} \exp \left(-\frac{S}{S_{M}}\right),
$$

the integral of Eq. (2) has been obtained by Rodgers (1968) and from that we easily find in our case that:

$$
A=\frac{1}{\delta \ln R} \int_{-\infty}^{\infty} d \nu\left[\ln \left(1+k_{\nu}\right)-\ln \left(1+\frac{k_{\nu}}{R}\right)\right],
$$

where

$$
k_{\nu}=S_{M} \sum_{i} a_{i}^{\prime} f_{i}(\nu)
$$

Here we will further assume that $f_{i}$ is given by the Lorentz line shape and, with a new parameter $\beta_{i}$, we have

$$
\begin{aligned}
1+k_{\nu} & =1+\frac{S_{M}}{\pi} \sum_{i} \frac{\alpha_{i} a_{i}{ }^{\prime}}{\nu^{2}+\alpha_{i}{ }^{2}} \\
& =\prod_{i} \frac{\nu^{2}+{\beta_{i}}^{2}}{\nu^{2}+{\alpha_{i}}^{2}} .
\end{aligned}
$$

To perform the integral in Eq. (9) we use the complex integral and $\nu$ is now an imaginary number. Assume that the order of the values of $\alpha_{i}$ is the same as that of $i$; that is, $\alpha_{1}<\alpha_{2}<\alpha_{3}<\cdots$. Since the left hand side of Eq. (11) is a monotonic function of $\nu^{2}$ in the range $-\alpha_{i+1}^{2}<\nu^{2}<-\alpha_{i}^{2}$, and approaches $-\infty$ for $\nu^{2} \rightarrow-\alpha_{i}^{2}$ and $+\infty$ for $\nu^{2} \rightarrow-\alpha_{i+1}^{2}$, it becomes zero at one point. This point is shown by $-\beta_{i}{ }^{2}$ in Fig. 1 together with the functional behavior of $k_{\nu}$ against $\nu^{2}$. In the range $-\infty<\nu^{2} \leq-\alpha_{N}^{2}$ (11) becomes unity for $\nu^{2} \rightarrow-\infty$. Thus the curve of $k_{\nu}$ 
crosses the horizontal line of -1 at $N$ of different points. All the values of ${\beta_{i}}^{2}$ are different as far as $\alpha_{i}$ are different from each other.

By a partial integral the first term in Eq. (9) is reduced to (see Rodgers, 1968)

$$
\begin{aligned}
-\frac{1}{\delta^{\prime}} & \int_{-\infty}^{\infty} \nu \frac{d}{d \nu} \ln \left(1+k_{\nu}\right) d \nu \\
& =-\frac{1}{\delta^{\prime}} \int_{-\infty}^{\infty} \frac{\nu}{1+k_{\nu}} \frac{d k_{\nu}}{d \nu} d \nu \\
& =-\frac{1}{\delta^{\prime}} \int_{-\infty}^{\infty} \sum_{i}\left(\frac{2 \nu^{2}}{\nu^{2}+\beta_{i}{ }^{2}}-\frac{2 \nu^{2}}{\nu^{2}+\alpha_{i}{ }^{2}}\right) d \nu \\
& =-\frac{1}{\delta^{\prime}} \int_{-\infty}^{\infty} \sum_{i}\left(\frac{2 \alpha_{i}{ }^{2}}{\nu^{2}+\alpha_{i}{ }^{2}}-\frac{2{\beta_{i}}^{2}}{\nu^{2}+\beta_{i}{ }^{2}}\right) d \nu
\end{aligned}
$$

$$
\delta^{\prime}=\delta \ln R
$$

The integrand in Eq. (12) has the poles of only the first rank. If we take a half circle of the path of integral on the complex plane, whose radius is infinity, the integral along the circle vanishes because the integrand becomes zero for $|\nu| \rightarrow \infty$. Then (12) becomes

$$
\frac{2 \pi}{\delta^{\prime}} \sum_{i}\left(\beta_{i}-\alpha_{i}\right)
$$

By defining $\beta_{i}{ }^{*}$ as

$$
\begin{aligned}
1+\frac{k_{\nu}}{R} & =1+\frac{S_{M}}{\pi R} \sum_{i} \frac{\alpha_{i} a_{i}{ }^{\prime}}{\nu^{2}+\alpha_{i}^{2}} \\
& =\prod_{i} \frac{\nu^{2}+\left(\beta_{i}{ }^{*}\right)^{2}}{\nu^{2}+\alpha_{i}{ }^{2}},
\end{aligned}
$$

we obtain similar result for the second term in Eq. (9) and finally obtain

$$
A=\frac{2 \pi}{\delta^{\prime}} \sum_{i}\left(\beta_{i}-\beta_{i}^{*}\right) .
$$

Since $R$ is generally a very large number (Malkmus, 1967) the left hand side of Eq. (14) approaches unity for such case, and $\beta_{i}{ }^{*}$ closely approaches $\alpha_{i}$. Thus, for a sufficiently large value of $R,(15)$ is approximated by

$$
A=\frac{2 \pi}{\delta^{\prime}} \sum_{i}\left(\beta_{i}-\alpha_{i}\right) \quad(R \rightarrow \infty) .
$$

In the following we will use this approximation for simplicity. The extension to the case of Eq. (15) may be easily made.

When $N=1$ we have, from Eq. (11),

$$
\beta_{1}=\alpha_{1} \sqrt{1+u_{1}},
$$

where $u$ is defined by

$$
u=\frac{S_{M} a^{\prime}}{\pi \alpha} .
$$

These lead to the well known Malkmus formula:

$$
A=\frac{2 \pi \alpha_{1}}{\delta^{\prime}}\left(\sqrt{1+u_{1}}-1\right) \text {. }
$$

When $N=2$ the solution becomes somewhat complicated as

$$
A=\frac{2 \pi}{\delta^{\prime}}\left(\beta_{1}+\beta_{2}-\alpha_{1}-\alpha_{2}\right),
$$

where two values of $\beta$ are given by

$$
\begin{aligned}
2 \beta_{1,2}{ }^{2} & =\alpha_{1}{ }^{2}\left(1+u_{1}\right)+\alpha_{2}{ }^{2}\left(1+u_{2}\right) \\
& \pm\left\{\left[\alpha_{1}{ }^{2}\left(1+u_{1}\right)+\alpha_{2}{ }^{2}\left(1+u_{2}\right)\right]^{2}\right. \\
& \left.-4 \alpha_{1}{ }^{2} \alpha_{2}{ }^{2}\left(1+u_{1}+u_{2}\right)\right\}^{\frac{1}{2}} .
\end{aligned}
$$

This is the formula that has already been obtained by Rodgers (1968).

It is easily confirmed that when $\alpha_{1}=\alpha_{2}$ Eq. (20) is reduced to (19) if we replace $u_{1}+u_{2}$ by $u_{1}$. For a larger value of $N$ than 2 the formula of $\beta_{i}$ suddenly becomes complicated or is impossible to obtain. So in Section 4 in this paper, where the atmosphere was divided into 40 homogeneous layers, we obtained the exact solution by a numerical procedure.

\subsection{Formulation for the exponential intensity distri- bution model}

In the exponential intensity distribution model $P(S)$ is given by

$$
P(S)=\frac{1}{\sigma} \exp \left(-\frac{S}{\sigma}\right) .
$$

If we again assume that the relative intensity distribution function is not changed layer to layer Eq. (2) becomes

$$
A=\frac{1}{\delta} \int_{-\infty}^{\infty} d \nu \frac{k_{\nu}}{k_{\nu}+1},
$$

where

$$
k_{\nu}=\sigma \sum_{i} a_{i}{ }^{\prime} f_{i}(\nu) .
$$

For the Lorentz line shape it becomes

$$
\frac{k_{\nu}}{1+k_{\nu}}=1-\prod_{i}^{N}\left(\nu^{2}+\alpha_{i}{ }^{2}\right) / \prod_{i}^{N}\left(\nu^{2}+{\beta_{i}}^{2}\right)
$$

where $\beta_{i}$ is defined as

$$
1+\frac{\sigma}{\pi} \sum_{i}^{N} \frac{\alpha_{i} a_{i}{ }^{\prime}}{\nu^{2}+\alpha_{i}^{2}}=\prod_{i}^{N} \frac{\nu^{2}+{\beta_{i}}^{2}}{\nu^{2}+{\alpha_{i}}^{2}} .
$$

Eq. (25) has a singular point of only the first rank since all ${\beta_{i}}^{2}$ are different as shown in Section 2.1. By taking the same contour of the integral as the case of the Malkmus model we have 


$$
A=\frac{\pi}{\delta} \sum_{i}^{N} \frac{\beta_{i}^{2}-\alpha_{i}^{2}}{\beta_{i}} \prod_{j \neq i}^{N} \frac{\alpha_{j}^{2}-\beta_{i}^{2}}{\beta_{j}^{2}-\beta_{i}^{2}} .
$$

When $N=1$ from Eq. (27)

$$
\begin{aligned}
& \beta_{1}=\alpha_{1} \sqrt{1+u_{1}}, \\
& u=\frac{\sigma a^{\prime}}{\pi \alpha} .
\end{aligned}
$$

The optical depth becomes

$$
A=\frac{\pi}{\delta} \frac{u_{1} \alpha_{1}}{\sqrt{1+u_{1}}} .
$$

This is the well known Mayer-Goody model. When $N=2$ it becomes

$$
A=\frac{\pi}{\delta} \frac{\left(u_{1} \alpha_{1}{ }^{2}+u_{2} \alpha_{2}{ }^{2}\right) \beta_{1} \beta_{2}+\alpha_{1}{ }^{2} \alpha_{2}{ }^{2}\left(u_{1}+u_{2}\right)}{\beta_{1} \beta_{2}\left(\beta_{1}+\beta_{2}\right)},
$$

where $\beta_{1,2}$ are given by the same formula as Eq. (21) except that we now use $u$ defined in Eq. (29). It is again easy to confirm that the Eq. (31) is reduced to (30) when $\alpha_{1}$ approaches $\alpha_{2}$.

The formula of the Mayer-Goody model for two homogeneous layers has also been derived by Plass (1965). However, its formula (Eq. (58) in his paper) is different from the present result (Eq. (31)). As a result, the formula of Plass (1965) is not reduced to a one-layer formula when $\alpha_{1}=\alpha_{2}$. The cause of this contradiction comes from the fact that in the paper of Plass (1965) values of the line intensity in individual layers are assumed to be uncorrelated. Mathematically, by this assumption, the single integral over line intensity in Eq. (2) of our paper is replaced by the multiple integral (Eq. (51) in the paper of Plass). However, it may be more reasonable in the real atmosphere to assume that the strong lines in one layer are also strong in another layer since the magnitude of the temperature change from layer to layer is not large.

\section{Comparison of the Godson and C-G meth- ods with the exact solution}

Godson (1953) proposed a method to calculate the transmittance of adjacent two homogeneous layers by

$$
\tilde{\mathcal{T}}_{1+2}=\tilde{\mathcal{T}}\left(a_{1}^{*}+a_{2}, p_{2}, T_{2}\right),
$$

where $p_{i}$ is the pressure of the $i$-th layer and $a_{1}^{*}$ is defined by

$$
\tilde{\mathcal{T}}\left(a_{1}^{*}, p_{2}, T_{2}\right)=\tilde{\mathcal{T}}\left(a_{1}, p_{1}, T_{1}\right) .
$$

That is, $a_{1}^{*}$ is the absorber amount of a layer (whose temperature and pressure are $T_{2}$ and $p_{2}$, respectively), which gives the same transmittance as that of the first layer. This procedure of Godson was

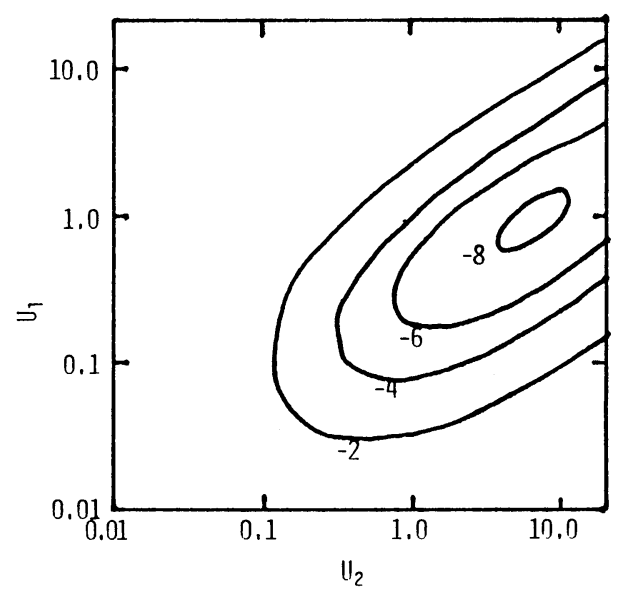

Fig. 2. The contour map of the percentage error of Godson's method against the optical thickness of two layers. The band model is the Malkmus model and the ratio of half width $\alpha_{1} / \alpha_{2}$ is 4.0 .

later used by some investigators as stated in Section 1; however, a critical discussion on the performance of this method has not been made yet. In this section we will investigate the characteristics of the accuracy of the Godson method together with the C-G method in a simplest case of two homogeneous layers, to which the analytical forms of exact solution are known as has already been shown in the preceding sections. The errors were calculated for various combinations of the values of $u_{1}$ and $u_{2}$.

Figure 2 shows an example of the error (in percentage) of the value of $A$ in the case of the Malkmus model, where the ratio of the pressures of two layers is 4.0, i.e., $\alpha_{1} / \alpha_{2}=4.0$. The maximum error appears at about $u_{1}=1.0$ and $u_{2}=8.0$. Although in actual application to atmospheric transmittance calculations we may not encounter such a combination of the values of $u_{1}$ and $u_{2}$, this maximum possible error may be an indicator of the performance of a model.

Figures 3 and 4 show the maximum possible error in $A$, and the values of $u_{1}$ and $u_{2}$ which lead to this error. Figure 3 is for the Malkmus model and Fig. 4 is for the exponential intensity model, respectively. The left-half part of figures is the region where line width of the first layer is smaller than that of the second, and vice-versa in the right half. Since the smaller line width generally means the smaller pressure, the figures show that the error becomes large when a larger absorber amount is present in the layer of lower pressure. This result suggests that the error is larger when the transmittance calculation is done upward from the ground to the top of the atmosphere than when it is done downward. However, when the number of layers is sufficiently large, where the line widths of adjacent two layers is nearly equal, the accuracies of the upward and downward meth- 


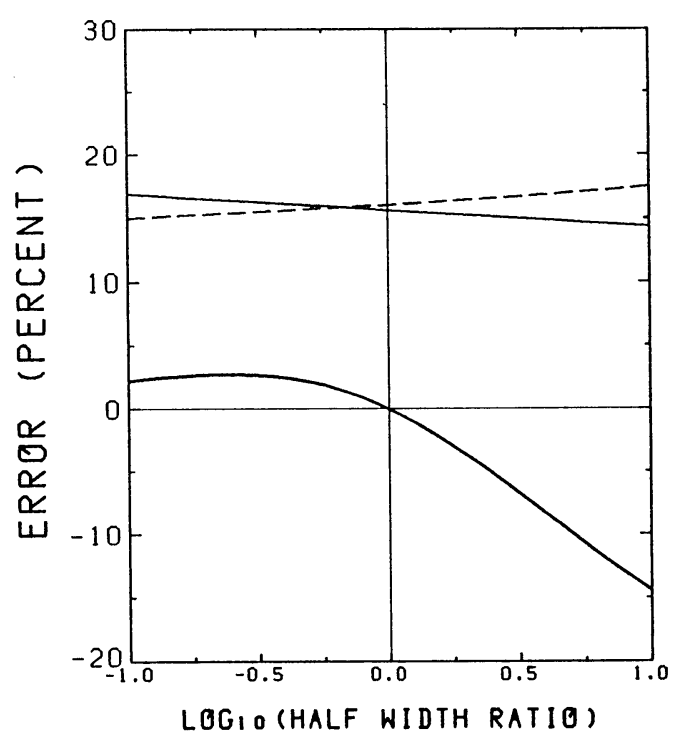

Fig. 3. The maximum possible error in the value of $A$ of Godson's method for the Malkmus intensity model in two homogeneous layers (solid thick line). The values $\ln (u)+15$ for $u_{1}$ and $u_{2}$, which lead to the maximum error, are shown by a solid thin line and dashed line, respectively.

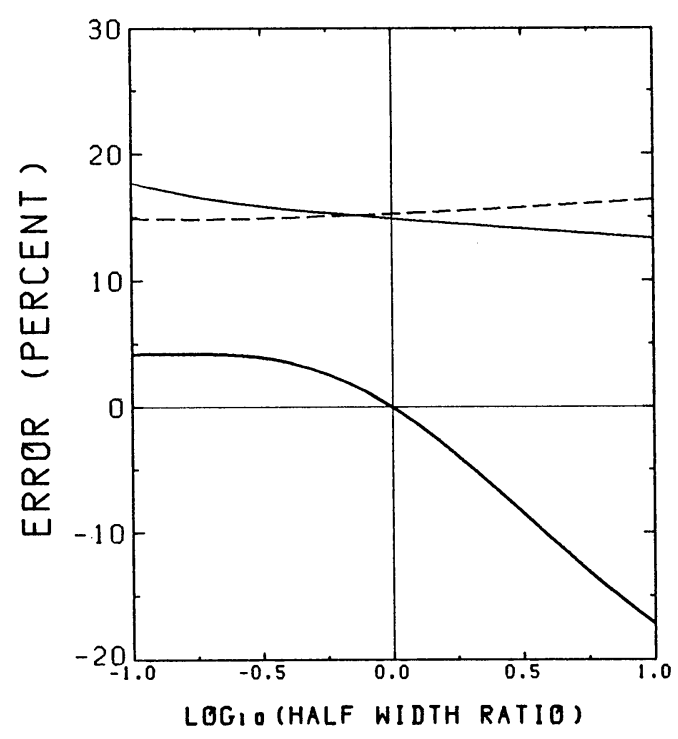

Fig. 4. As in Fig. 3 except for the model of the exponential intensity distribution.

ods are roughly same except the sign. In this case the Godson's original method (Godson, 1953) is a reasonable one, where he adopted the average of the upward and downward methods.

Figures 5 and 6 show a similar result for the C$\mathrm{G}$ method. In this method the effective absorber amount $\tilde{a}$ and the mean line width $\tilde{\alpha}$ are given respectively by

$$
\tilde{a}=a_{1}+a_{2}
$$

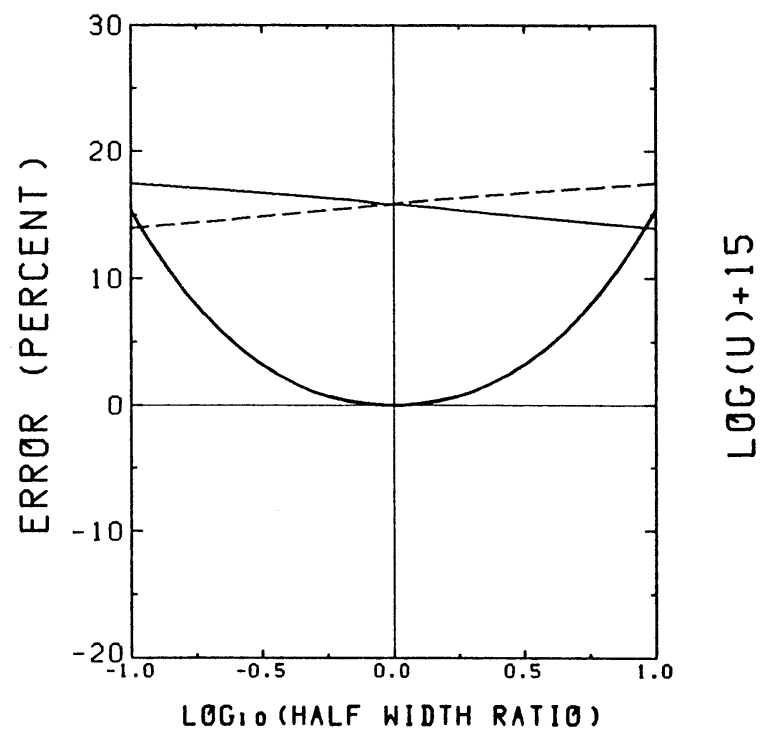

Fig. 5. As in Fig. 3 except for the CurtisGodson method.

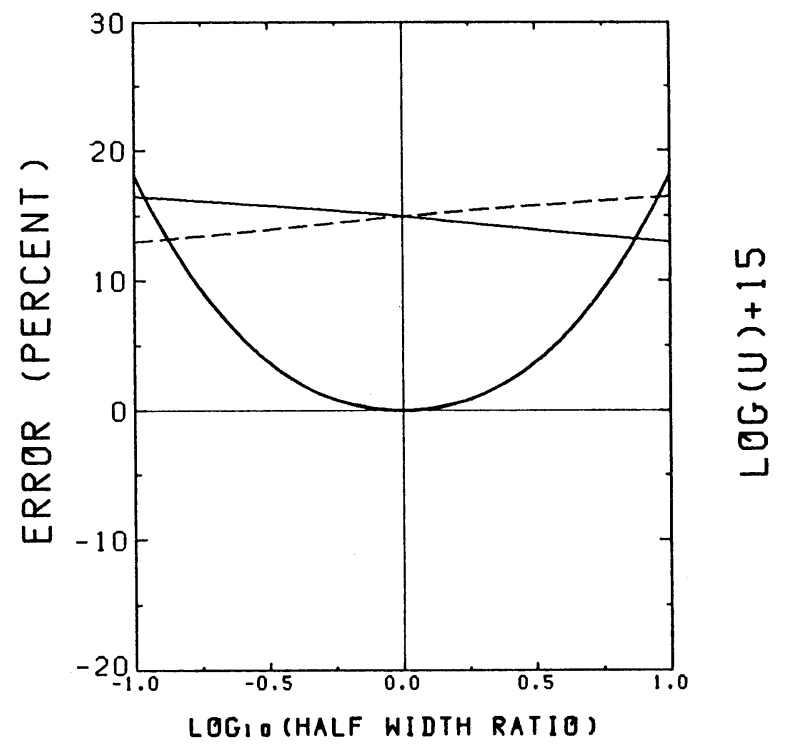

Fig. 6. As in Fig. 4 except for the CurtisGodson method.

and

$$
\tilde{\alpha}=\frac{a_{1} \alpha_{1}+a_{2} \alpha_{2}}{a_{1}+a_{2}}
$$

Thus in the C-G method the upward and downward transmittance calculations result in the same value, as can be seen in figures. The maximum possible error of the C-G method is slightly larger than that of the Godson method especially in the case where the pressure of the first layer is smaller than that of the second (i.e., in the case of downward procedure). 

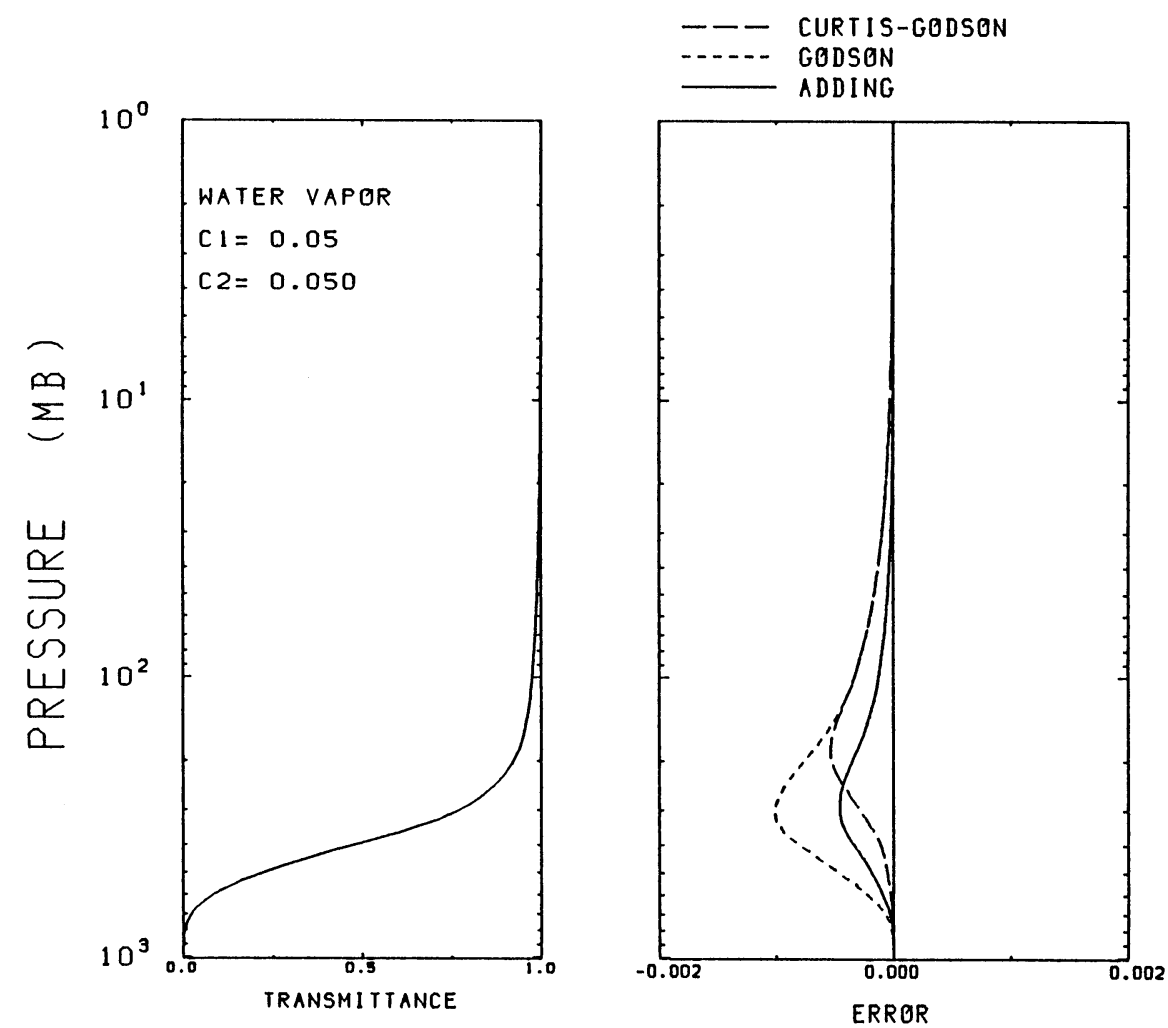

Fig. 7. The exact solution of the water vapor transmittance (left panel) and the fractional error of the three approximate models for the Malkmus band model at US standard atmosphere (right panel).

\section{Adding procedure to multi-homogeneous layers}

When the number of layers is large the values of $\beta_{i}$ must be obtained numerically, which requires much computation time since the process to obtain $\beta_{i}$ involves an iterative calculation such as the Newtonian interpolation. In this section we propose an approximate but fast computational procedure similar to the Godson method. Using the analytical formulae for one and two homogeneous layers derived in the Section 2 we can sequentially obtain the transmittance through multi-homogeneous layers. Let us consider first the Malkmus model. The exact solution for two layers is given by Eq. (20). Consider a hypothetical layer whose temperature and pressure are the same as those of the second layer but the absorber amount is $a_{2}^{*}$ instead of $a_{2}$. The optical thickness of this hypothetical layer is given by, from Eq. (19),

$$
A=\frac{2 \pi \alpha_{2}}{\delta^{\prime}}\left(\sqrt{1+u_{2}^{*}}-1\right)
$$

where $u_{2}^{*}=S_{M} a_{2}^{*} / \pi \alpha_{2}$. On the other hand Eq. (20) is rewritten as

$$
A=\frac{2 \pi \alpha_{2}}{\delta^{\prime}}\left(\beta_{1}^{\prime}+\beta_{2}^{\prime}-1-\rho\right),
$$

where

$$
\begin{aligned}
& \rho=\frac{\alpha_{1}}{\alpha_{2}}, \\
& 2\left(\beta_{1,2}\right)^{2}=2\left(\frac{\beta_{1,2}}{\alpha_{2}}\right)^{2} \\
& \quad=\rho^{2}\left(1+u_{1}\right)+\left(1+u_{2}\right) \\
& \quad \pm \sqrt{\left[\rho^{2}\left(1+u_{1}\right)+\left(1+u_{2}\right)\right]^{2}-4 \rho^{2}\left(1+u_{1}+u_{2}\right)} .
\end{aligned}
$$

$A$ in Eq. (36) becomes equal to that in Eq. (37) if we give $u_{2}{ }^{*}$ by

$$
u_{2}^{*}=\left(\beta_{1}^{\prime}+\beta_{2}^{\prime}-1-\rho\right)^{2}-1 .
$$

Similarly for the exponential intensity model $u_{2}^{*}$ is given by

$$
\begin{aligned}
& u_{2}{ }^{*}=\frac{1}{2}\left[B^{2}+\sqrt{B^{4}+4 B^{2}}\right], \\
& B=\frac{\left(\rho^{2} u_{1}+u_{2}\right) \beta_{1}{ }^{\prime} \beta_{2}{ }^{\prime}+\rho^{2}\left(u_{1}+u_{2}\right)}{\beta_{1}{ }^{\prime} \beta_{2}{ }^{\prime}\left(\beta_{1}{ }^{\prime}+\beta_{2}{ }^{\prime}\right)} .
\end{aligned}
$$

Using this hypothetical single layer whose transmittance is equivalent to that through two layers, we can sequentially calculate the transmittance for any number of layers. In the present work we will call this sequential procedure the adding method. The difference between the present adding method and that of Godson's is that in the former the transmittance of the single-layer model equivalent to two 


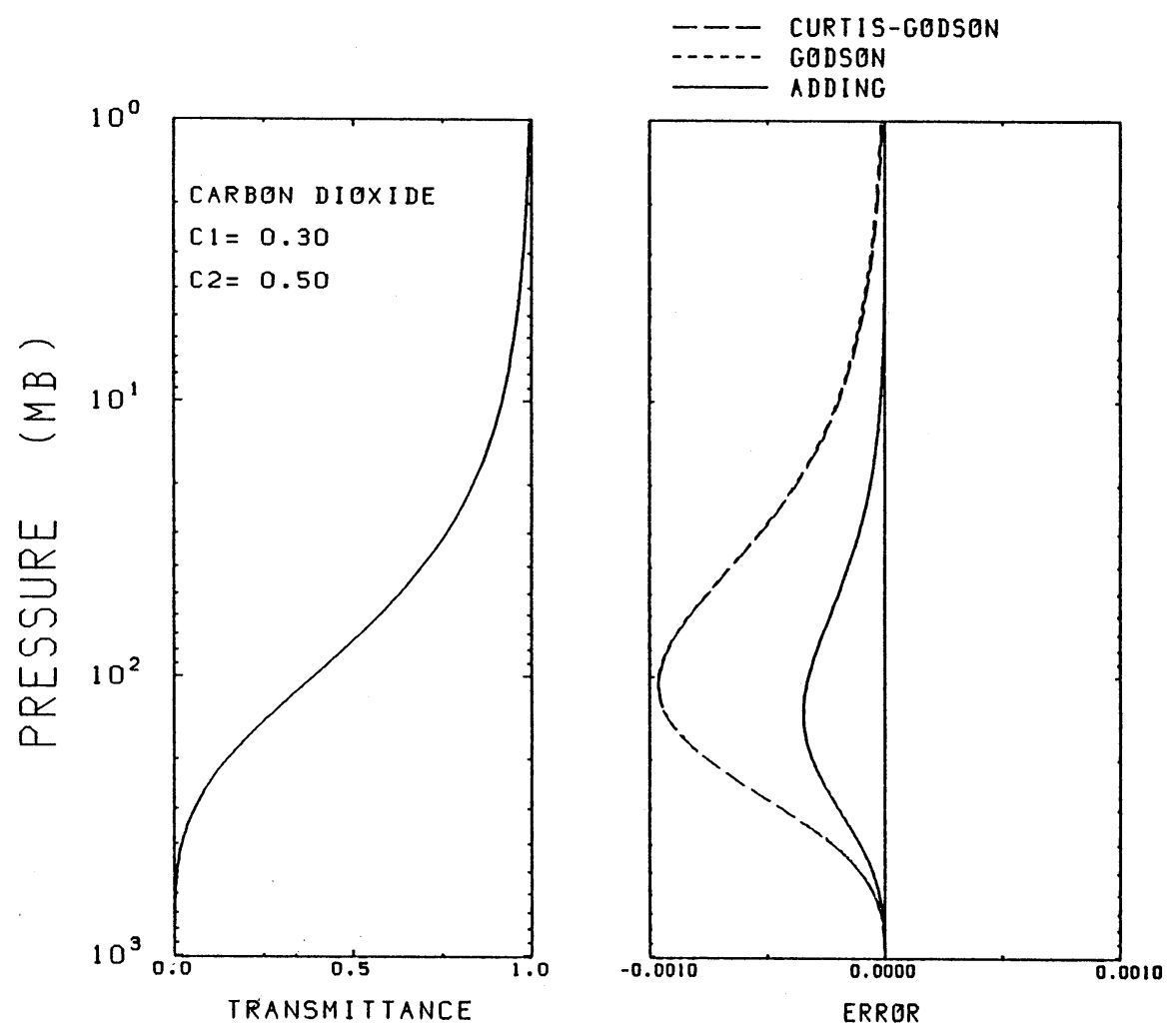

Fig. 8. As in Fig. 7 except for carbon dioxide.

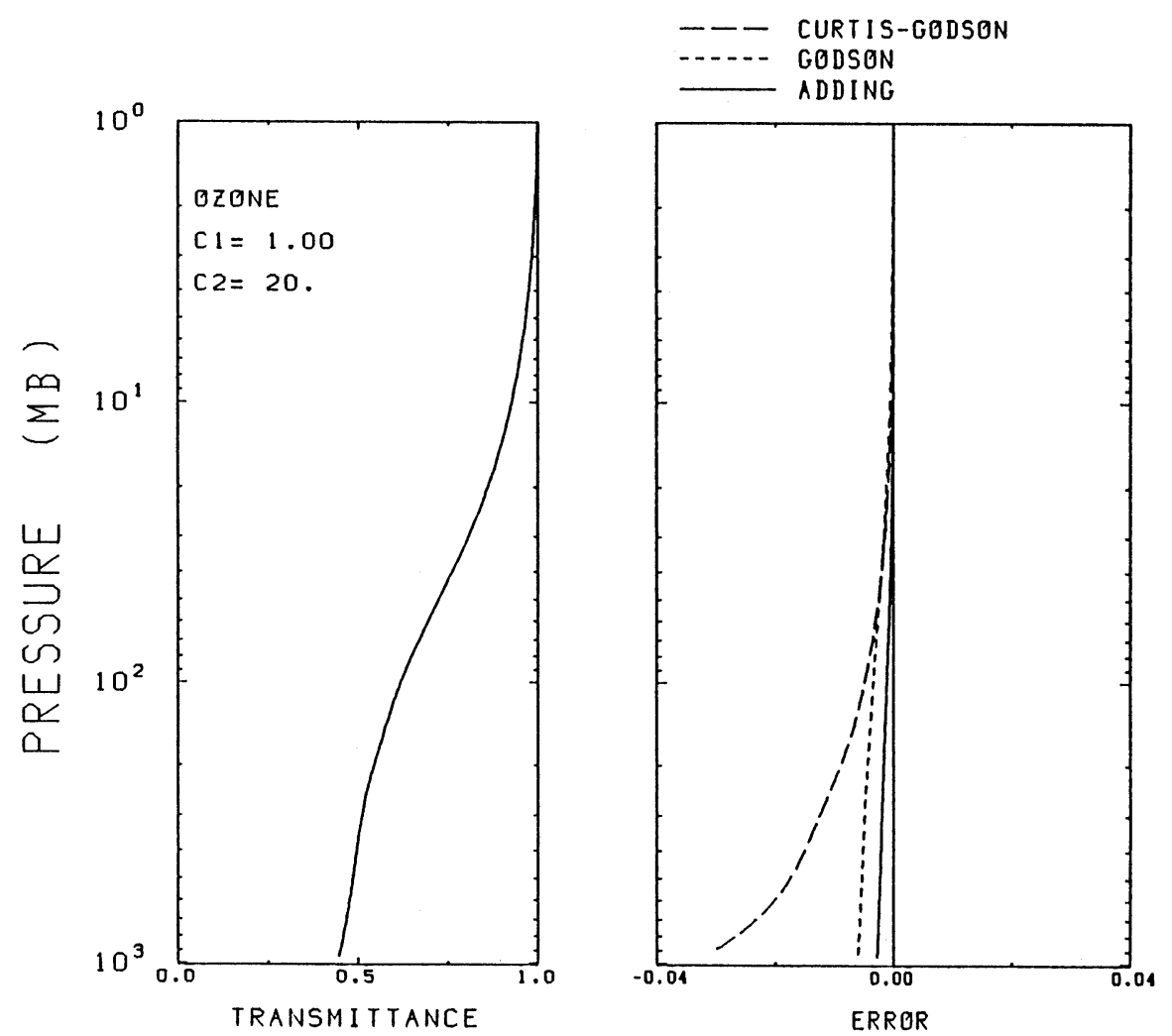

Fig. 9. As in Fig. 7 except for ozone. 

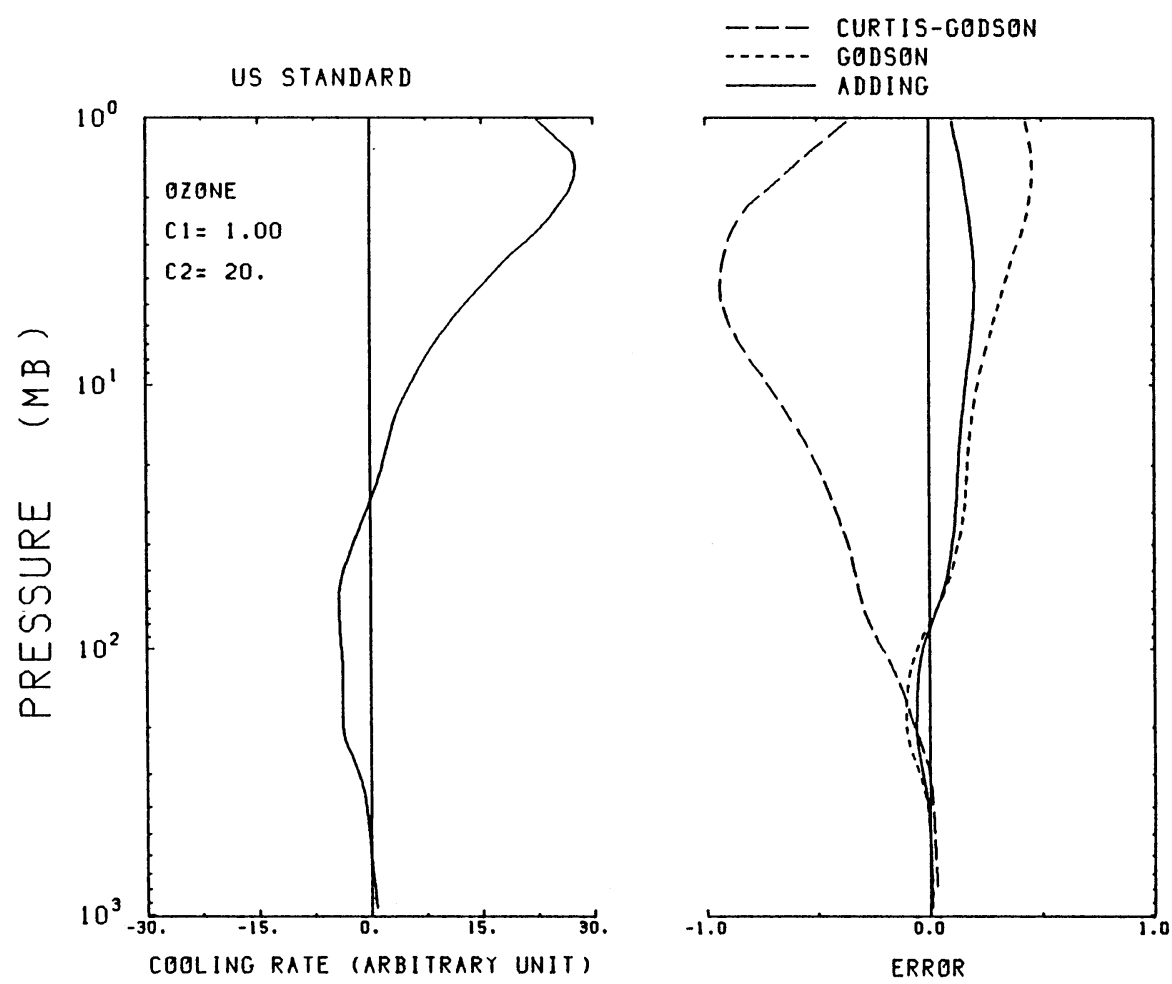

Fig. 10. Cooling rate of the Malkmus intensity model in arbitrary units for ozone (left panel) and the error of three approximate methods (right panel).

layers is the exact one, whereas in the latter Eq. (33) is only the approximation.

Some examples of the transmittance error (deviation from the exact solution) of the present adding method together with those of the Godson and C-G methods are shown in Figs. 7 through 9 for different three types of absorption bands. In these figures $C_{1}$ and $C_{2}$ are related to the line width at the standard pressure, $\alpha^{\circ}$, the intensity $S_{M}$ and mean line interval $\delta$ as

$$
\begin{aligned}
& C_{1}=\frac{2 \pi \alpha^{\circ}}{\delta \ln R}, \\
& C_{2}=\frac{S_{M}}{\pi \alpha^{\circ}} C_{1}^{2} .
\end{aligned}
$$

The parameters $C_{1}$ and $C_{2}$ in Figs. 7, 8 and 9 are calculated from typical absorption bands of water vapor, carbon dioxide and ozone, respectively. The values of $\alpha^{\circ}$ are assumed to be $0.1,0.07$ and $0.1 \mathrm{~cm}^{-1} / \mathrm{atm}$ for water vapor, carbon dioxide and ozone, respectively. The mean intensity $\sigma$ is given by

$$
\sigma=\frac{S_{M}}{4} .
$$

This relation is obtained by the requirement that the transmittances of the Malkmus and exponential intensity model are same at sufficiently small and large values of the amount $a$. It can be seen for all three gases that the present adding method is of better accuracy than the other two. The accuracy of the ozone transmittance is very poor compared to those of water vapor and carbon dioxide for all three methods.

The errors of the cooling rate calculation for ozone with the Malkmus and exponential intensity models are shown in Figs. 10 and 11, respectively. Since in the present work the calculation has been made for a selected band strength, and the band interval is not specified, only the relative values of cooling rate are shown. It is seen that the accuracy of the present adding method is again better than the others.

\section{Summary and remarks}

An exact solution of the radiative transfer through multi-homogeneous atmospheric layers has been developed in the framework of the random-band model with the Lorentz line shape, in which the relative line intensity distribution is conserved throughout the layers. Simple analytical formulae have been derived for smaller number of layers. It has been found that the formula of Plass (1965) derived for two layers under the random model of the exponential intensity distribution is different from the present result. The formula of Plass (1965) is not adequate because for two layers it does not reduce to the formula for a single layer when the pressure and temperature of two layers become equal.

Since the analytical formula of the exact solution cannot be obtained for large number of layers, a sequential procedure has been proposed to achieve a fast computation. The accuracy of present adding 

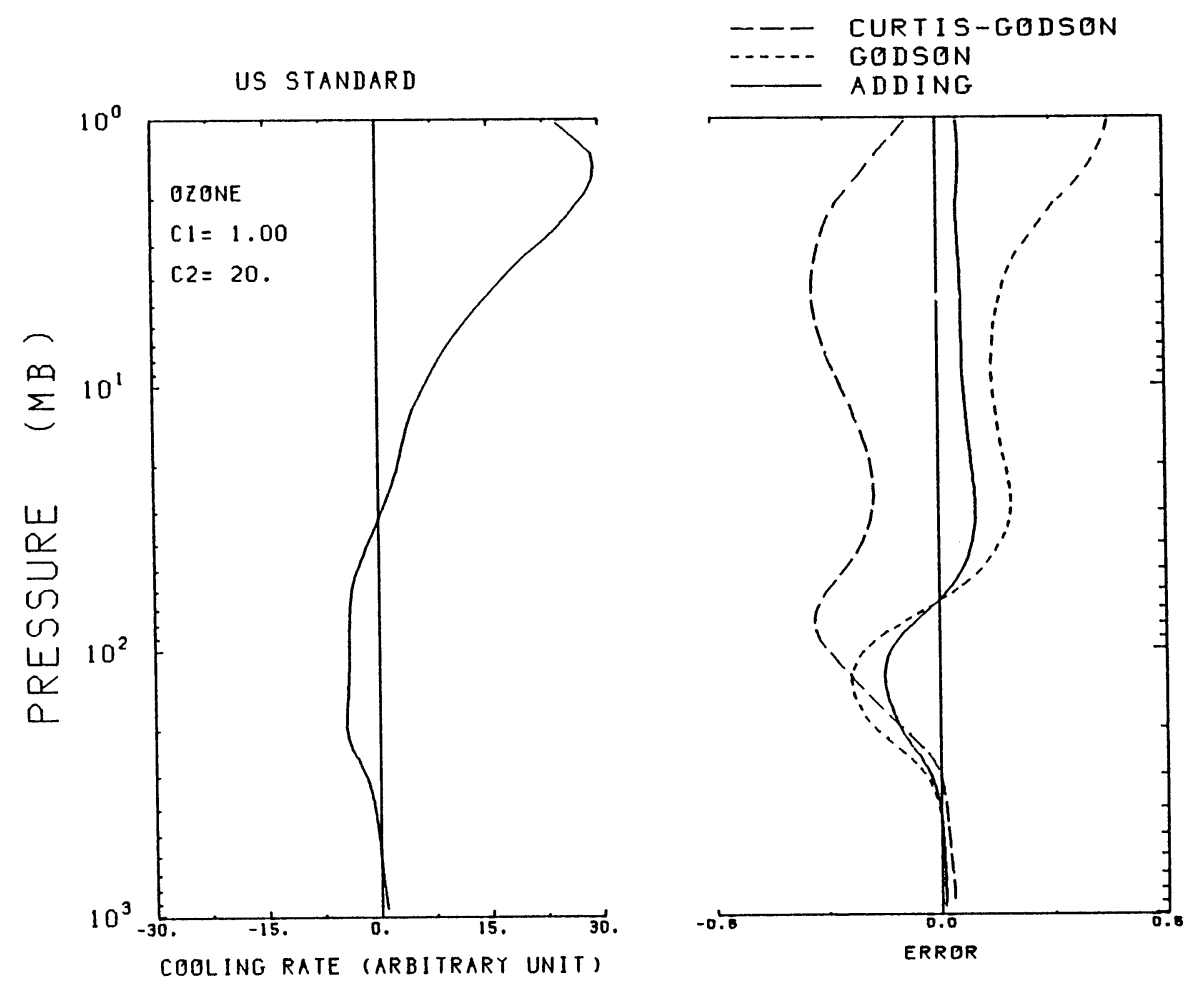

Fig. 11. As in Fig. 10 except for the exponential intensity distribution model.

method is better than the Godson or C-G method.

Random-band models with various parameters and band intervals have been used as shown in the Intercomparison of Radiation Codes in Climate Models (see, WMO, 1984 or Luther et al., 1988) and in recent work of Tjemkes and Duynkerke (1990). The adding method presented in this work may be applied to these random-band models.

The formulation of the present work has been based on the Lorentz line shape. However, since the random-band models can be applied to the Voigt line shape by emperical fitting, as has been done in Shibata and Aoki (1989), the application of the present adding methods may be extended to a higher altitude in the atmosphere by such means.

\section{References}

Aoki, T., 1979: Approximate formula for the narrow band transmission function. J. Meteor. Soc. Japan, 57, 203-206.

Clark, J. and W. Hitschfeld, 1964: Heating rate due to ozone computed by the Curtis-Godson approximation. Quart. J. Roy. Meteor. Soc., 90, 96-100.

Curtis, A.R., 1952: Discussion of a statistical model for water vapour absorption. Quart. J. Roy. Meteor. Soc., 78, 638-640.

Godson, W.L., 1953: The evaluation of infra-red radiative fluxes due to atmospheric water vapour, Quart. J. Roy. Meteor. Soc., 79, 367-379.

Goody, R.M., 1964: Atmospheric radiation. Oxford University Press, Oxford.

Goody, R.M. and Y.L. Yung, 1989: Atmospheric radiation-Theoretical basis, Second edition. Oxford
University Press, Oxford.

Kurian, J.G., Z. Shippony and S.K. Mitra, 1977: Transmission function for infrared radiative transfer in inhomogeneous atmosphere. Quart. J. Roy. Meteor. Soc., 103, 511-517.

Luther, F.M., R.G. Ellingson, Y. Fouquart, S. Fels, N.A. Scott, and W.J. Wiscome, 1988: Intercomparison of radiation codes in climate models (ICRCCM): Longwave clear sky results-A workshop summary. Bull. Amer. Meteor. Soc., 69, 40-48.

Malkmus, W., 1967: Random Lorentz band model with exponential tailed $S^{-1}$ line-intensity distribution. $J$. Opt. Soc. Amer., 57, 323-329.

Plass, G.N., 1965: Spectral band absorptance of radiation traversing two or more cells in series. Appl. Opt., 4, 69-78.

Rodgers, C.D., 1968: Some extension of the new random model for molecular band transmission. Quart. J. Roy. Meteor. Soc., 94, 99-102.

Shibata, K. and T. Aoki, 1989: An infrared radiative scheme for the numerical models of weather and climate. J. Geophys. Res., 94, 14923-14943.

Tjemkes, S.A. and F.T.M. Nieuwstadt, 1990: A longwave radiation model for the nocturnal boundary layer. J. Geophys. Res., 95, 867-872.

Walshaw, C.D. and C.D. Rodgers, 1963: The effect of the Curtis-Godson approximation on the accuracy of radiative heating rate calculation. Quart. J. Roy. Meteor. Soc., 89, 122-130.

Weinreb, W.M. and A.C. Neuendorffer, 1973: Method to apply homogeneous-path transmittance models to inhomogeneous atmospheres. J. Atmos. Sci., 39, 1532-1544.

World Meteorological Organization, 1984: Longwave clear-sky calculations. World Climate Research Pro- 
gramme Report WCP-93, 37pp.

Yamamoto, G. and M. Aida, 1970: Transmission in a non-homogeneous atmosphere with an absorbing gas of constant mixing of constant mixing ratio. $J$. Quant. Spectros. Radiat. Transfer, 10, 593-608.
Yamamoto, G., M. Aida and S. Yamamoto, 1972: Improved Curtis-Godson approximation in a nonhomogeneous atmosphere. J. Atmos. Sci., 29, 11501155 .

\section{バンドモデルを不均質大気に適用するいくつかの方法について 青木忠生・柴田清孝 \\ (気象研究所)}

不均質大気中における赤外放射伝達式の厳密解がローレンツ線をベースにしたランダムモデルに対して 開発された。乙れとの比較によって、従来使われているカーティス・ゴードソン法やゴードソンの方法の 精度を調べた。との結果ゴードソンの遂次計算法の誤差は透過率計算が、大気の下に向かって行われるか 上に向かって行われるかで異なることが示された。

2 層に対する解析的厳密解を使った新しい逐次計算法が提唱されている。ての新しい逐次計算法は従来 のカーティス・ゴードソンやゴードソン法より、水蒸気、炭酸ガス、オゾンの放射伝達計算に打いて高精 度であるととが示されている。 